\title{
HUDSON VALLEY LABORATORY
}

\section{Highland, New York}

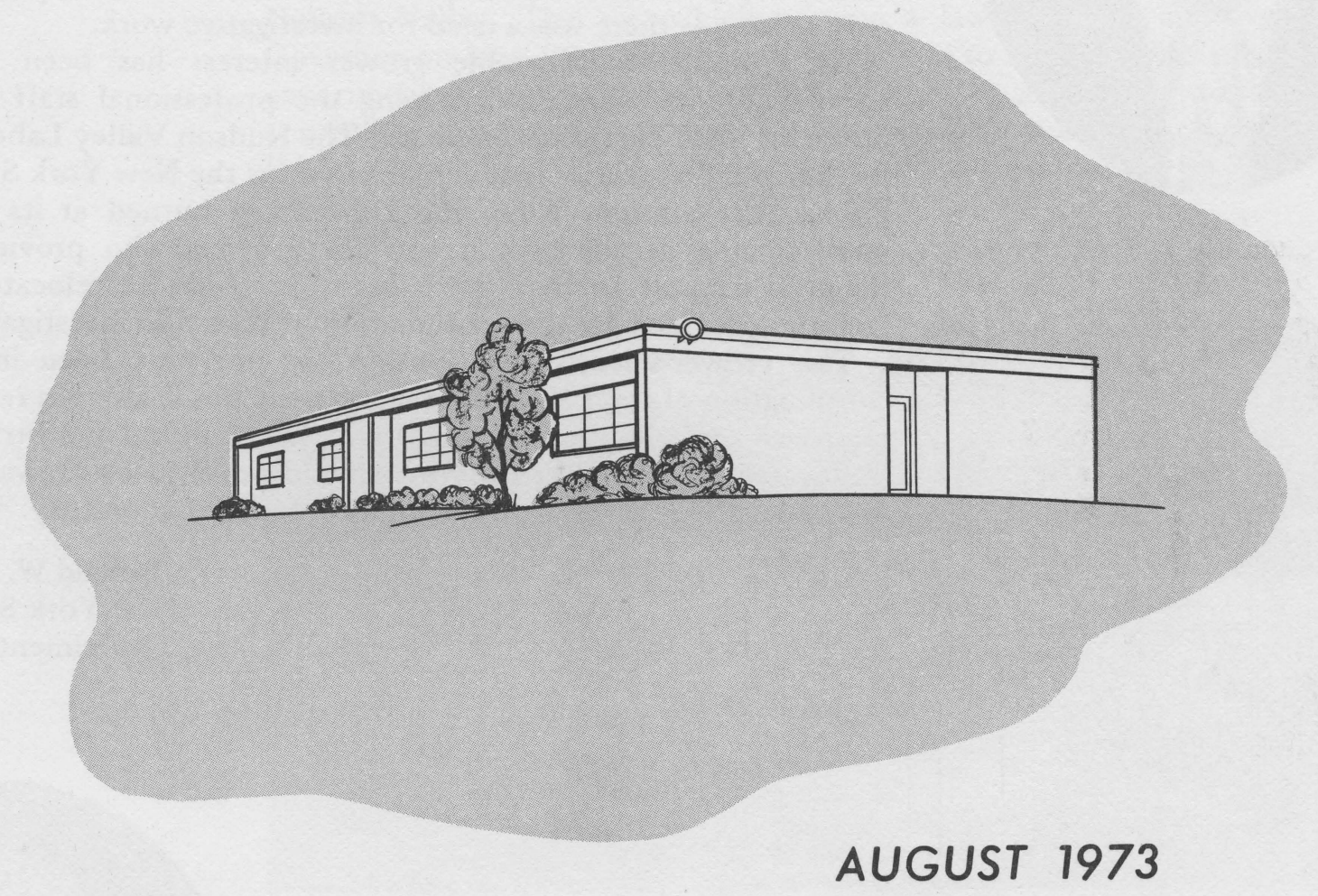

New York State Agricultural Experiment Station, Geneva, A Division of the New York State College of Agriculture and Life Sciences, A Statutory College of the State University, Cornell University, Ithaca 


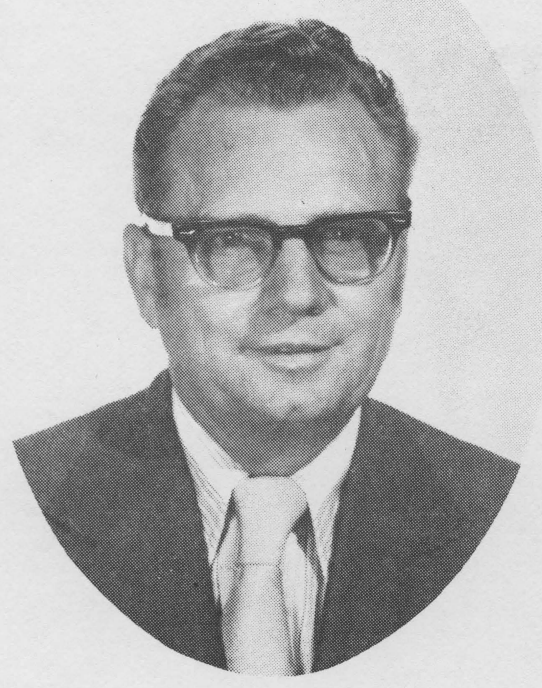

Cornell University and its New York State Agricultural Experiment Station at Geneva are especially proud of the accomplishments of the Hudson Valley Laboratory. Currently, the staff at the Laboratory is responsible for research that affects more than 50,000 acres of prime agricultural land in the Valley that is used for the production of fruits and vegetables.

It is a tribute to the State Legislature of New York that in 1923 the members saw the need for having a special research facility located in this area to study and solve problems unique to the climate, topography, and growing of horticultural crops. The mandate from the 1923 Legislature also clearly stated that this facility was to be established and properly staffed for only as long as there was a need for investigative work.

As a result, considerable grower interest has been aroused in the Laboratory, its work, and helping the professional staff determine what problems need particular emphasis. The Hudson Valley Laboratory is among the best success stories that can be cited for the New York State Agricultural Experiment Station. When the Laboratory burned at its former location more than a decade ago, it was the growers who provided considerable financial support so that the Laboratory could be relocated and excellent facilities provided for the continuation of scientific investigations.

This grower-scientist relationship has not only been important to the continuation of the Laboratory's existence, but it also has resulted in a much improved and significantly important horticultural industry in the Hudson Valley region. The next 50 years should prove just as rewarding to all who are so deeply involved with the Hudson Valley Laboratory.

Donald W. Barton, Director New York State Agricultural Experiment Station, Geneva

As spokesman for the fruit growers of eastern New York, I would like to express our appreciation for the leadership and support given our eastern New York apple industry by the staff at both Cornell University and its New York State Agricultural Experiment Station at Geneva. The unique involvement of fruit growers with the Hudson Valley Laboratory typifies the very best combination of research, extension, and commercial fruit growing. It is our hope that together we can forge new and innovative programs to meet the challenges of the next 50 years.

John Hotaling, President Hudson Valley Research Laboratory, Inc.

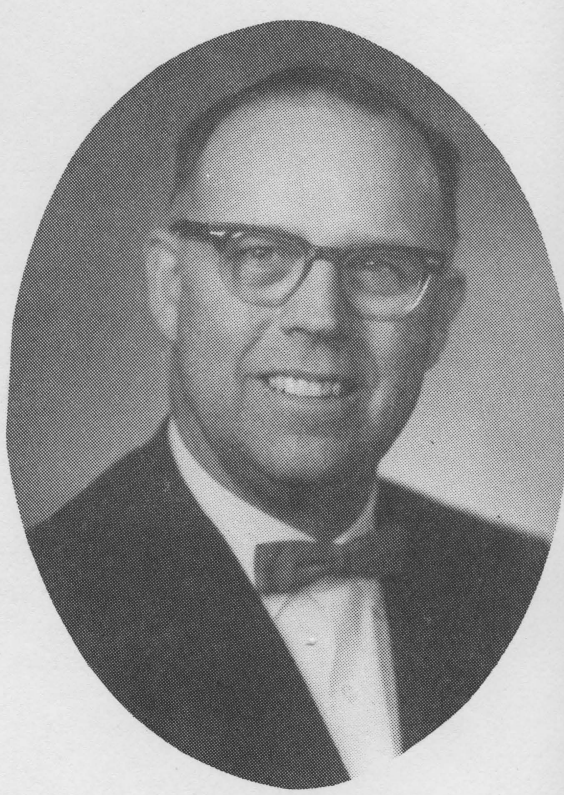


In 1923, the New York State Agricultural Experiment Station at Geneva and the State Legislature saw the need for establishing a laboratory in the Hudson Valley. The act, which became a law with the approval of the Governor on May 22, 1923 stated, "there was to be provided a place for the experimental study of the problems of increasing the production and controlling the diseases and injurious insects of the horticultural crops of the Hudson River Valley, and making appropriation therefor."

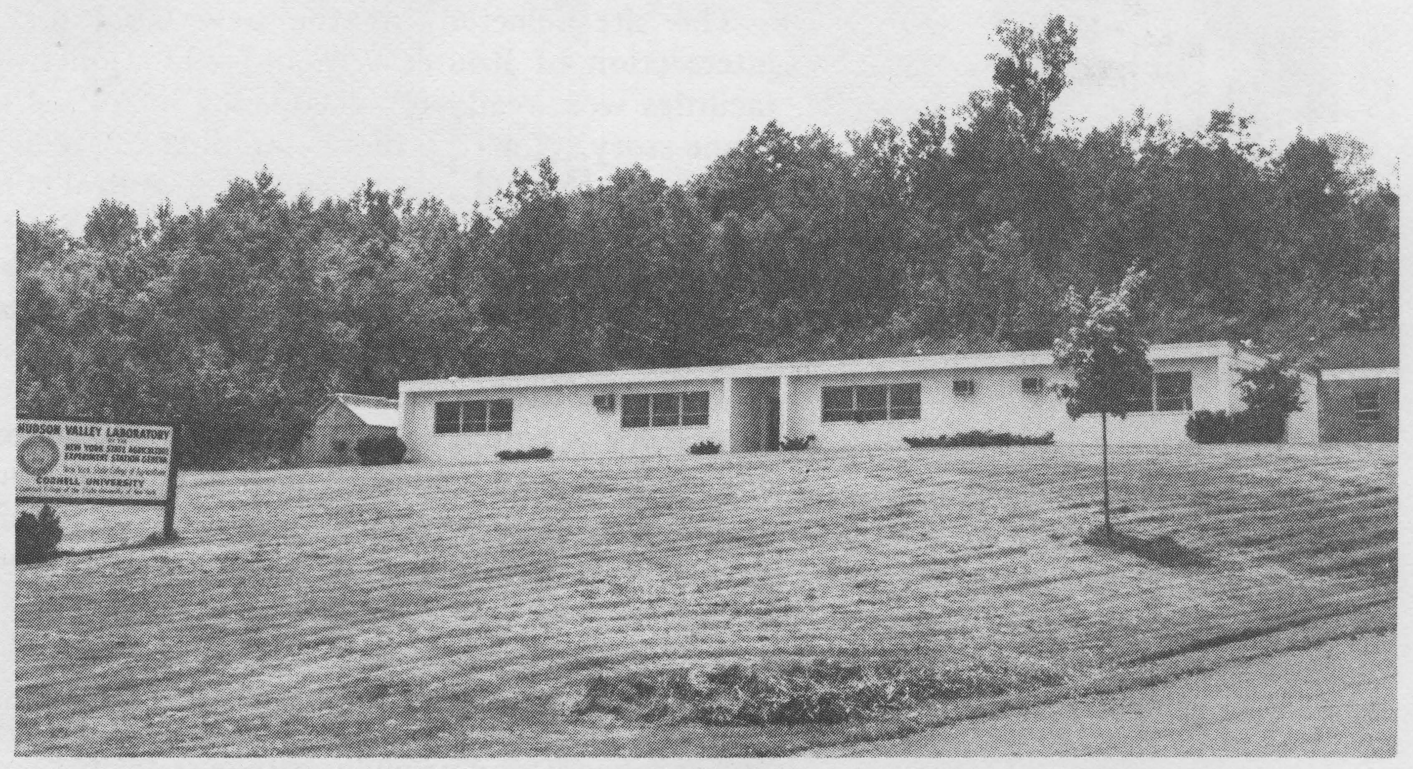

Figure 1.-Hudson Valley Laboratory

This law opened the door for the Station's Board of Control to "rent suitable lands and buildings within the fruit growing district of the Hudson River Valley, to employ the necessary scientists and laborers, and to purchase necessary equipment and provide proper facilities for the study of the problems of maintaining and improving the productivity of the soil, of securing improved varieties of fruits adapted to the soil and climate of the region, and of controlling the diseases and insect pests of the horticultural crops of the district."

It is of interest to note that the Station was to rent lands and buildings, not purchase them. This clearly indicated that the Laboratory was to remain only as long as it took to solve any important local problems. To date, there have always been more problems than time and, as a result, the Laboratory is essentially a permanent part of eastern New York horticulture.

In the 50 years of its existence, the Laboratory has had many homes. Initially, it was located in Highland, but later moved to the Vassar College 
campus, and then to Marple Road in Poughkeepsie. In 1942, the Laboratory was forced to move again, and it was at this time that the Hudson Valley Horticultural Research Cooperative (later renamed the Hudson Valley Research Laboratory, Inc.) was organized.

During the first 20 years, growers throughout eastern New York had benefited greatly from the outstanding research programs at the Laboratory. They considered the continued operation of the Laboratory to be essential because new problems were constantly developing in the fruit and vegetable industries in that part of the State. Through the Hudson Valley Horticultural Research Cooperative, the growers purchased an abandoned schoolhouse on Cottage Road in Poughkeepsie. This building was leased to Cornell University for use by the Laboratory. This was the beginning of a unique partnership between the horticultural industry and the Agricultural Experiment Station that has been and continues to be of great mutual benefit.

The importance of this relationship was emphasized in February 1962 when fire gutted the Laboratory building and destroyed valuable equipment and years of irreplaceable research data. The Hudson Valley Research Laboratory, Inc. promptly agreed to purchase land for a new laboratory and to construct an $\$ 80,000$ physical plant. Cornell agreed to lease the new buildings and to purchase additional acreage adjacent to the building site for use for experimental fruit and vegetable plantings.

The site selected for the new laboratory was at Highland near the intersection of Routes 9-W and 299. Construction began in 1963, and the facilities were ready for occupancy in August of that year. The laboratory is a one-story, concrete block building 38 feet wide and 111 feet long. The offices are located on one side of a central corridor with the laboratories on the other side. This plan was adopted as a result of experiences during the fire in the old building where offices and laboratories were combined and flammable materials added greatly to the damage to office equipment and records located in the same rooms.

The laboratory building has six offices and five laboratories. Each laboratory is equipped with hot and cold running water, LP gas, compressed air, and vacuum lines. There are also two insect-rearing rooms with equipment to control temperature and humidity within a narrow range. Attached to one end of the laboratory is a fiberglass greenhouse that is used for studying certain nutritional and insect and disease problems.

A second building is located adjacent to the laboratory. It is also of concrete block construction and is 126 feet long and 24 feet wide. This building houses one office, a workshop, a storage room for spray materials and fertilizers, and provides garage space for eight vehicles.

Figure 2.-Equipment storage, garage facilities, spray shed, and cooperative extension agent's office are located in building behind main Laboratory.

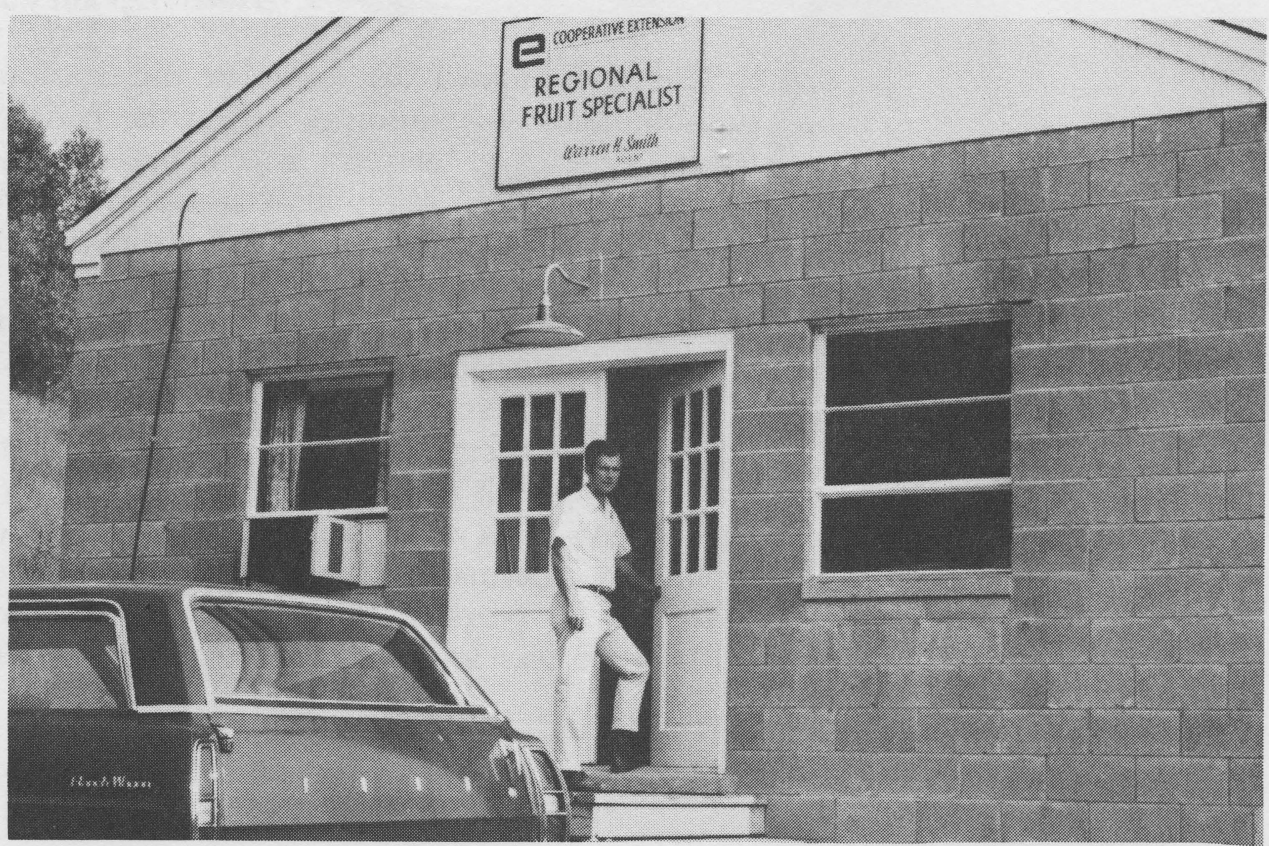




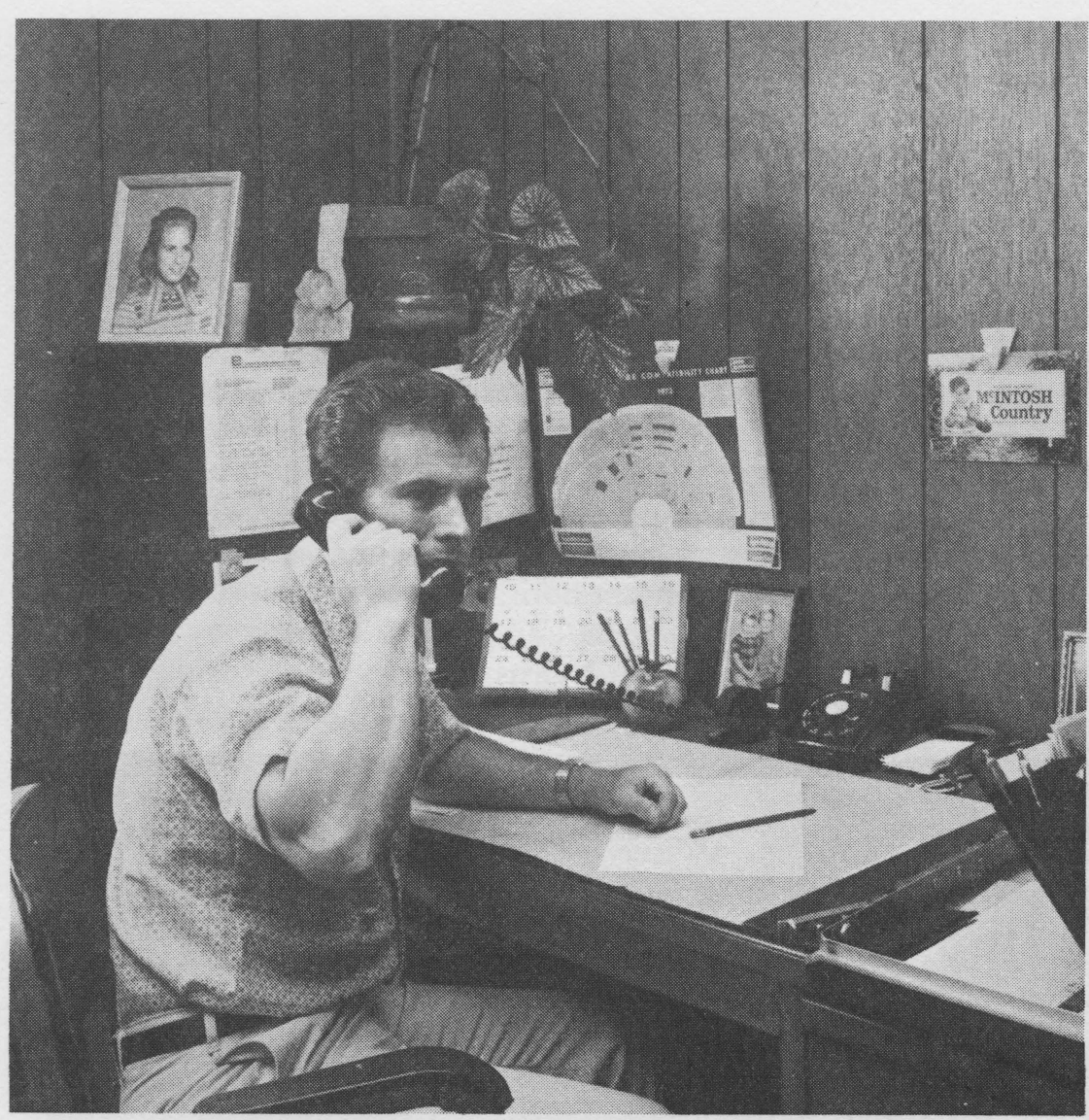

Figure 3.-Constant communication is maintained between Laboratory personnel and growers primarily through the Cooperative Extension Agent, Warren Smith.

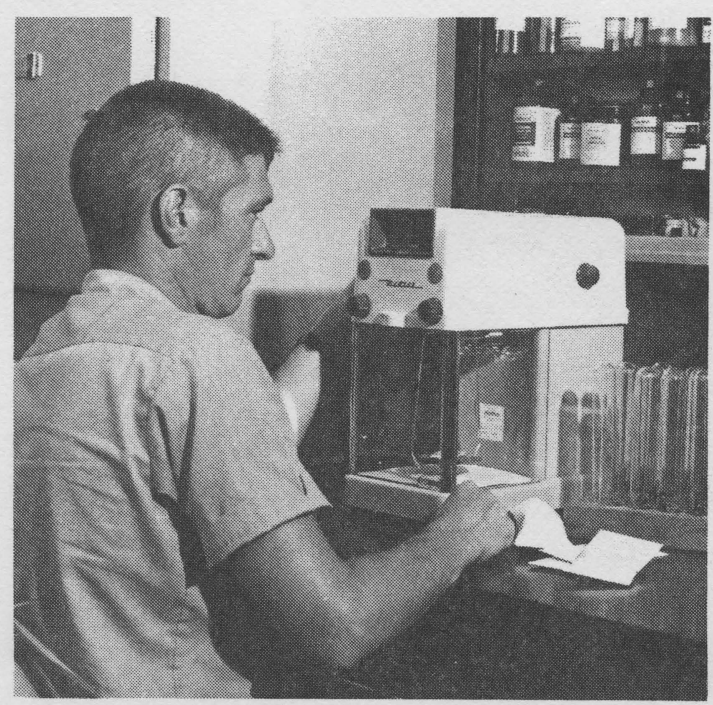

Figure 5.-Specialized facilities and equipment, such as this balance being used for leaf analysis studies, allow research personnel to study all problems peculiar to fruit and vegetable growing in the Hudson Valley.

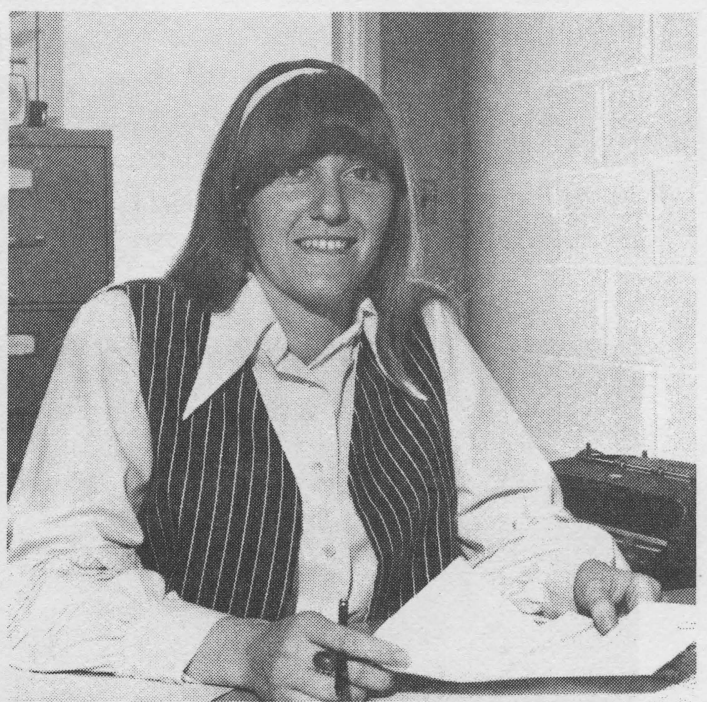

Figure 4.-Cora Sita serves as Laboratory secretary and receptionist.

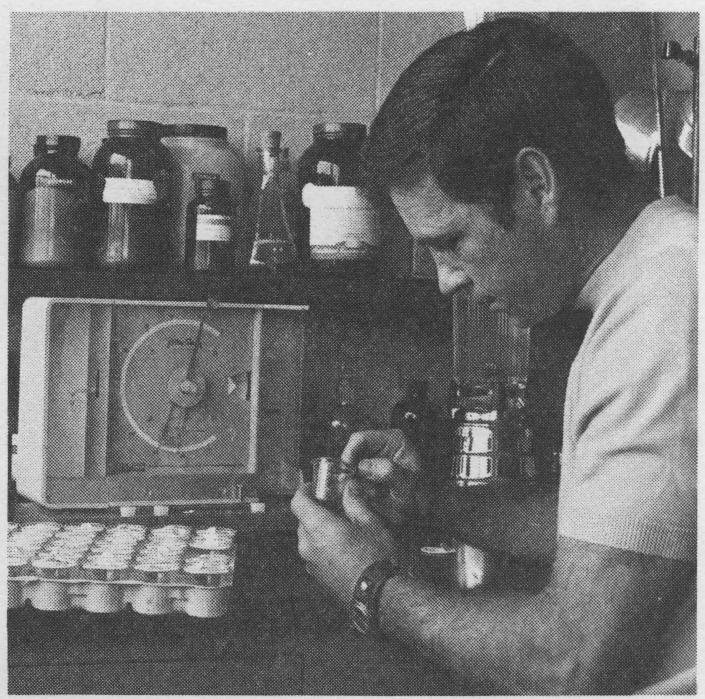

Figure 6.-Using controlled temperature insect rearing rooms, Richard Straub, entomologist, can maintain cultures of the most important insect species prevalent in the Valley. 
Most of the experimental work has always been conducted in commercial orchards. It has usually been advantageous to study the problems where they developed, and growers have willingly provided land, trees, and fruit for study, even though this usually resulted in some financial loss. However, it is also necessary to maintain some experimental plantings at the Laboratory for testing new spray materials not yet approved for commercial use and for certain other studies that might cause serious inconvenience or significant economic loss in commercial plantings.

Approximately 17 acres adjacent to the Laboratory is devoted to experimental plantings. The site, atop a picturesque hill, provides good air drainage in all directions. The soil is Cossayuna gravelly loam, which is considered to be one of the better orchard soils of the Hudson Valley. Near the center of the plantings, there is a pole barn for the storage of sprayers, tractors, and other farm equipment. A pond provides water for spraying.

While a small acreage is planted to sweet corn, most of this land is in fruit. Included are apples, pears, peaches, cherries, and prunes. These trees are used for testing new spray materials, studies of virus diseases, monitoring insect populations, and investigations of nutritional and physiological problems.

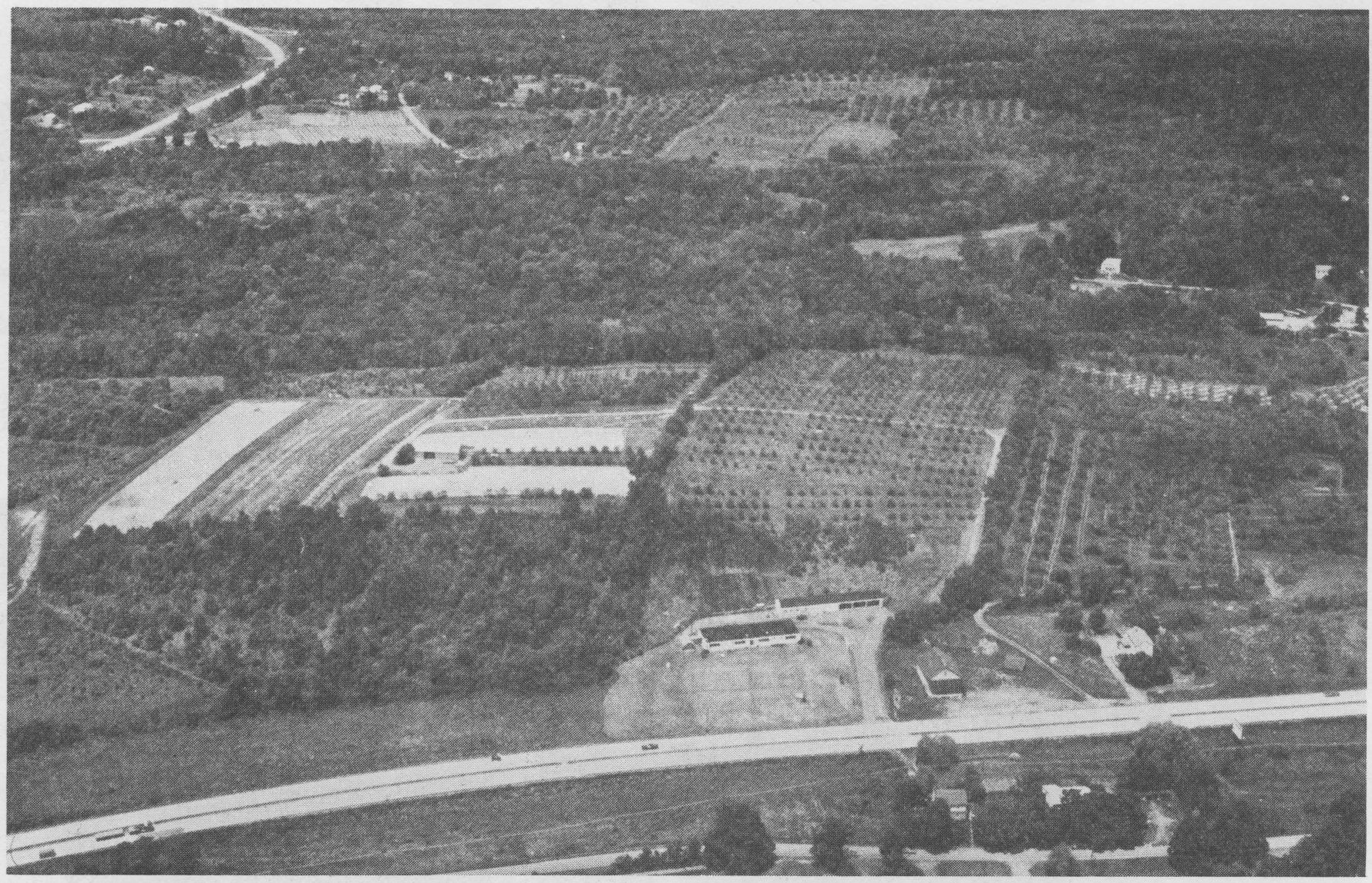

Figure 7.-Aerial of Hudson Valley Laboratory and surrounding 22 acres of land.

The primary responsibility of the Laboratory, as indicated in the original act of the Legislature, is to the commercial horticultural industry. The area has been expanded somewhat since 1923, and it is now more accurately described as "eastern New York" with significant work on Long Island, the Albany-Saratoga area, and the Champlain Valley. The emphasis remains, however, on the problems of the industry rather than on service to the individual grower. Though the primary objective is research, an obligation to assist growers in the evaluation and commercial application of research results is obvious, and the staff at the Laboratory has always participated in 
Extension programs as time permitted. To further improve and strengthen the liaison between research and the horticultural industry, a district Fruit Extension Agent was stationed at the Laboratory in 1970.

Past research at the Hudson Valley Laboratory has provided local growers, and growers in other areas as well, with invaluable guidance in insect and disease control and cultural practices. In the past 50 years, the fruit industry and its problems have changed dramatically, but the role of the Laboratory is unchanged. Much of the research at the Agricultural Experiment Station at Geneva is directed at producing fruits and vegetables for processing. However, in eastern New York, the demand is for fresh commodities, and the problems facing these growers are not always the same as those in other parts of the State. The Hudson Valley Laboratory provides the basic link between New York's agricultural research and those growers who produce their crops primarily for the fresh market. The importance of local research for fresh market crops is illustrated by the continued strong support of the Hudson Valley Research Laboratory, Inc. This organization has recently purchased an additional 8 acres adjacent to the present Laboratory to provide for future expansion.

Fruits and vegetables are a big industry in eastern New York. Apples, pears, grapes, plums and prunes, sweet cherries, peaches, and sweet corn are the major commodities. Apples lead the group with an annual production that approaches 10 million bushels and accounts for 40 per cent of the State's apple crop. The farm value of eastern New York's apple crop is estimated at $\$ 25,000,000$. The acreage in other fruits is a modest 4,100 , as compared with 28,300 in apples, but the per acre value of these crops is comparable to that of apples. The farm value of the fresh market sweet corn crop is nearly $\$ 2,500,000$.

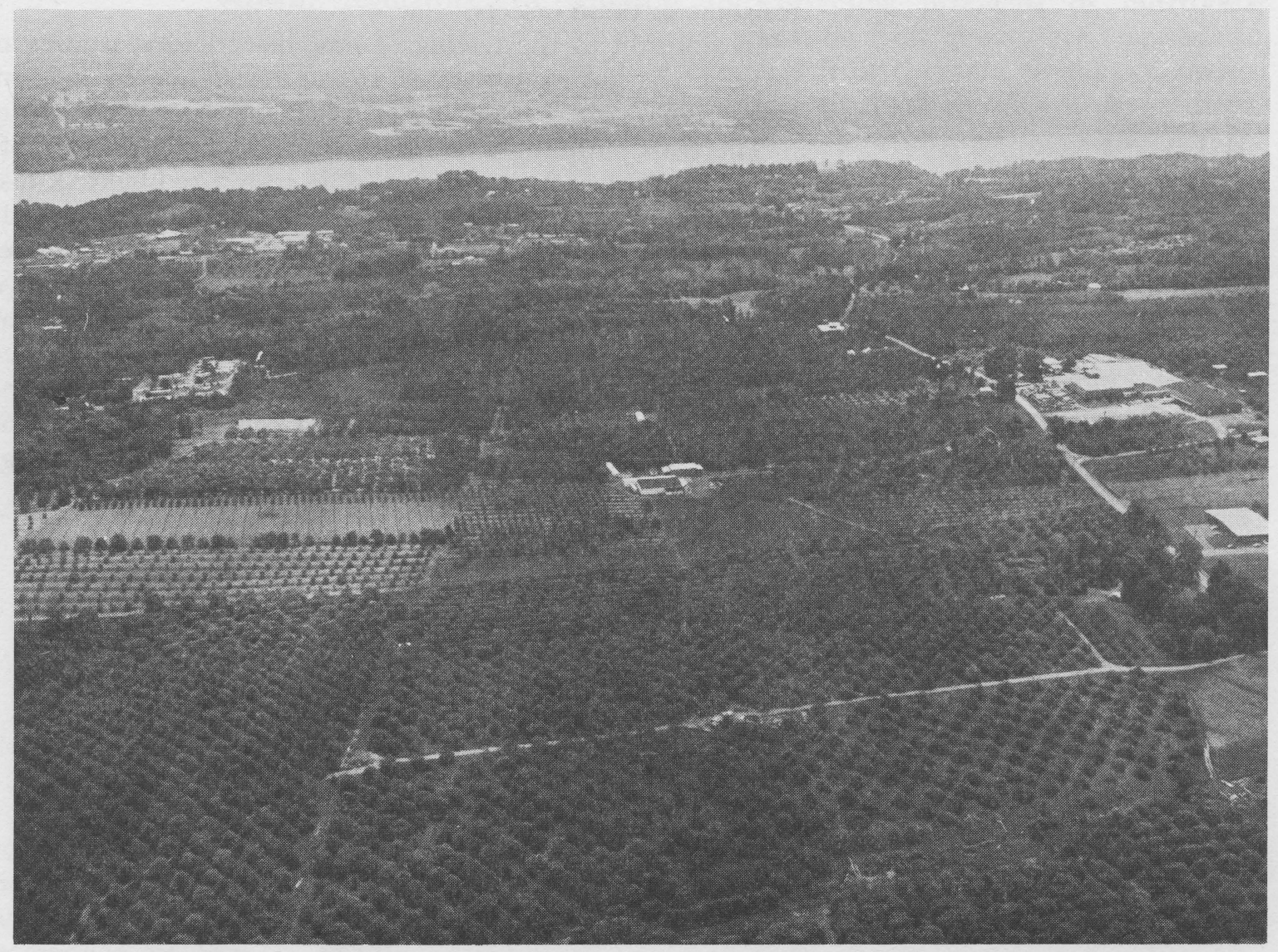

Figure 8.-Part of more than 32,000 commercial fruit acreage served by the Hudson Valley Laboratory. Hudson River can be seen in background. 


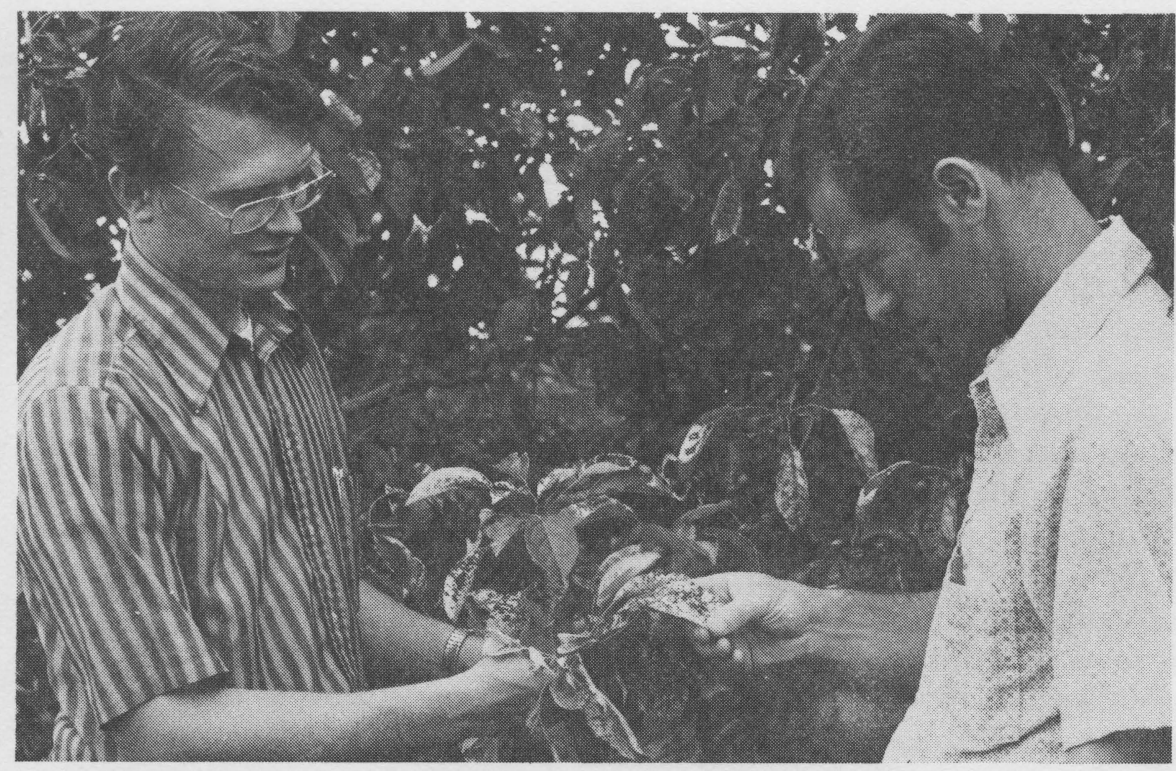

Figure 9.-Roger Pearson, plant pathologist, and Warren Smith, District Fruit Cooperative Extension Agent stationed at the Laboratory, look at tree infected with apple mosaic virus, one of many disease problems facing Hudson Valley growers.

The problems associated with the production of these crops are numerous and diverse. This is reflected in the broad research program pursued by the present staff of one vegetable entomologist, one fruit entomologist, one fruit plant pathologist, and two pomologists. This staff is assisted by three technicians and one secretary.

The vegetable entomologist is concerned largely with the biology and control of the European corn borer, corn earworm, fall armyworm, and the corn leaf aphid. The emphasis is on economic control of these sweet corn insect pests with minimum insecticide usage. A major part of the research program is also directed toward the development of strains of sweet corn resistant to these insects.

In addition to the testing of new insecticides, studies in fruit entomology include the investigation of insect resistance to certain insecticides, the evaluation of pheromone insect traps, and integrated pest control.

The fruit pathologist is currently conducting studies of the epidemiology and control of such diseases as apple scab, fire blight, X-disease of peach, and black rot of grapes. In addition, new fungicides and application techniques are being tested and scab-resistant varieties of apples are being evaluated.

The fruit entomologist and pathologist cooperate in efforts to develop reduced spray schedules. A significant reduction in the amount of pesticides required for economic pest control is desirable from the standpoint of the grower because this reduces production costs. It is equally desirable from the standpoint of the ecologist because this minimizes possible environmental effects. Of necessity, such approaches as pest management, integrated control, reduced rates, longer intervals between sprays, and alternate row spraying are being evaluated.

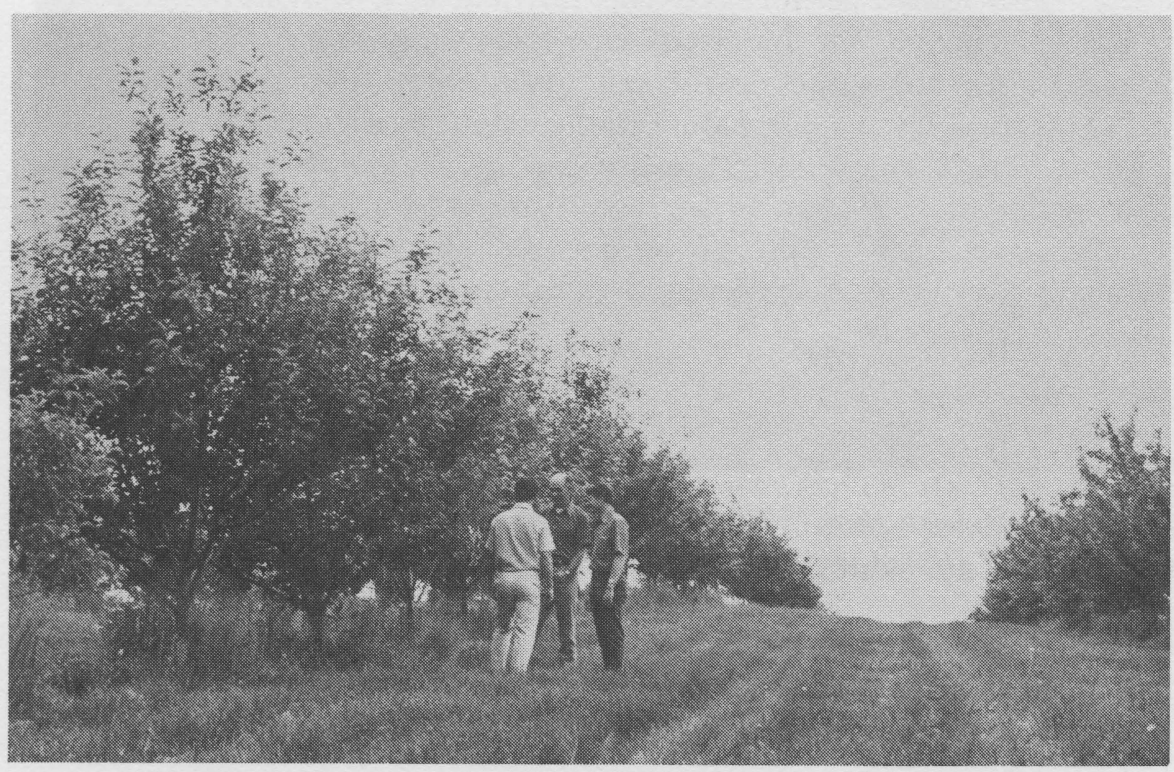

Figure 10.-A portion of the plantings at the Laboratory. Laboratory personnel and commercial growers cooperate extensively in providing additional research acreage. 


\section{About the Station...}

When established in 1882, State legislators could not have foreseen that the New York State Agricultural Experiment Station at Geneva would ever have the renown distinction it enjoys today. In fact, it was only through the diligent efforts of a few that the Experiment Station was ever started.

Today, the institution is known throughout the world as one of the great horticultural research experiment stations. Its staff of more than 60 professional scientists and 200 other technicians and assistants is working on more than 200 projects. The results of these efforts determine to a large extent the direction of today's agriculture in New York State and will form the design for tomorrow's.

The Experiment Station is an integral part of the New York State College of Agriculture and Life Sciences, a Statutory College of the State University of New York at Cornell University. Research work at the Geneva Station concentrates largely on the production, protection, and utilization of food crops grown for processing. Scientists undertake to develop high yielding, disease resistant varieties of fruits and vegetables that will make high quality products for the consumer. A seed testing service is available for farmers, nurserymen, and dealers. There is a comparable service with feeds and fertilizers. To accomplish all this work, more than 600 acres of land is maintained by the Station for field trials.

Research at the institution is divided among six departments; namely, Entomology, Plant Pathology, Pomology and Viticulture, Seed Investigations, Vegetable Crops, and Food Science and Technology. Also located at Geneva is a Regional Plant Introduction Station operated under the auspices of the U. S. Department of Agriculture, Washington, D. C.

Many years ago, the administration at Geneva saw the need for establishing units of the Station at strategic points in New York. The first such unit was located at Fredonia in the heart of a large grape producing area. About 10 years later, in 1923, the Hudson Valley Laboratory was established at Highland by act of the Legislature. Its primary objective was to help solve the problems facing the growers in eastern New York's fruit and vegetable industry.

The history of not only the Laboratory but of the commodities grown in the Hudson Valley is unique, and it is with a great deal of pride that we hold this collective relationship between our Laboratory here and the many growers in the area. 


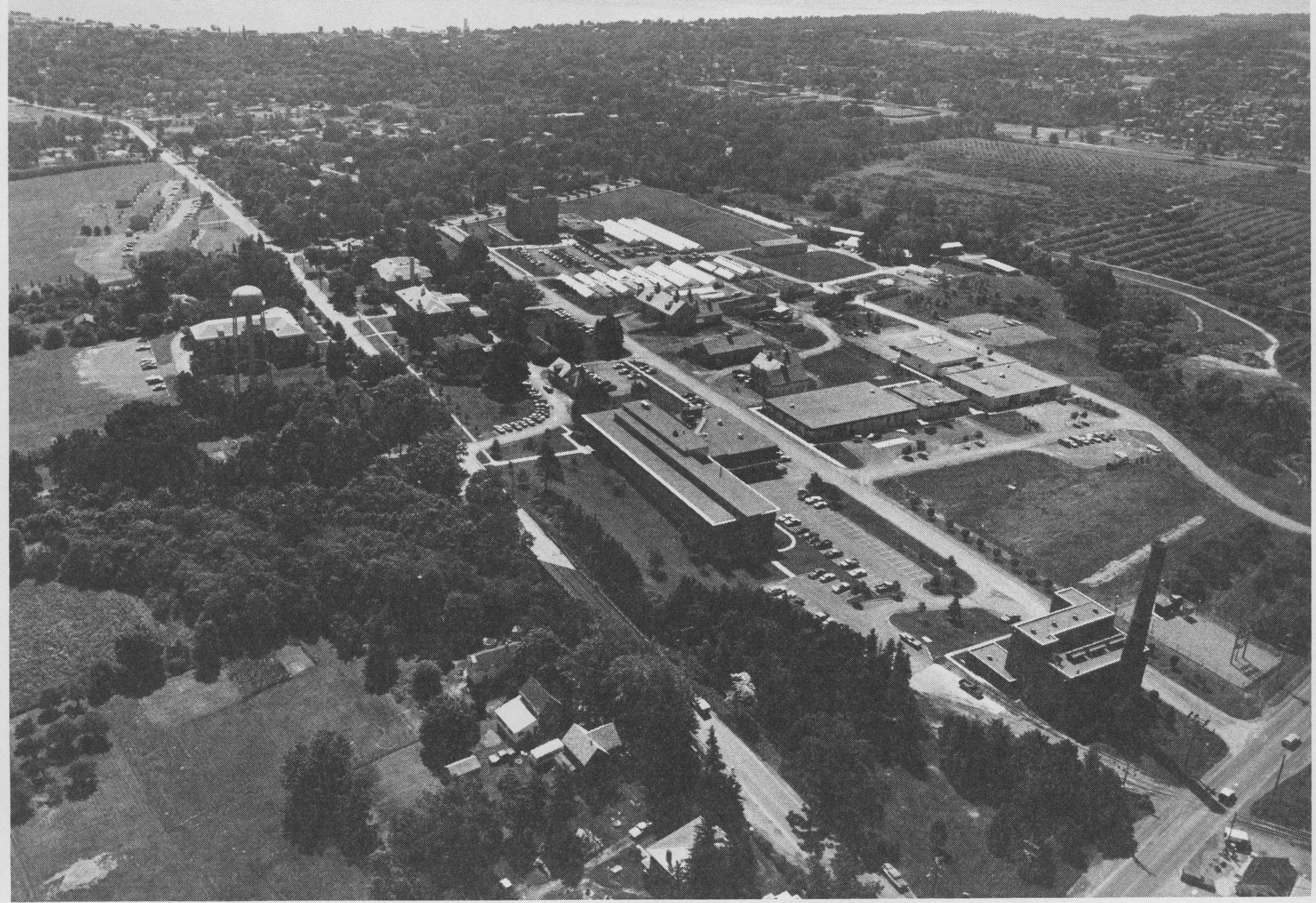

Figure 14.-Aerial view of the New York State Agricultural Experiment Station, Geneva. 
- 